\title{
Understanding the psychosocial profile of women with fibromyalgia syndrome
}

\author{
Jill Shuster $\mathrm{MA}^{1,2}$, Jana McCormack BA ${ }^{1}$, Rebecca Pillai Riddell PhD ${ }^{1,3}$, Maggie E Toplak PhD ${ }^{1,2}$
}

\begin{abstract}
J Shuster, J McCormack, R Pillai Riddell, ME Toplak. Understanding the psychosocial profile of women with fibromyalgia syndrome. Pain Res Manage 2009;14(3):239-245.
\end{abstract}

\begin{abstract}
Fibromyalgia syndrome (FMS) is a disease with a complex etiology characterized by symptoms of widespread pain and fatigue. FMS is more common in women. Both depression and anxiety have been found to be independently associated with the severity of pain in symptoms of FMS. The goal of the present study was to examine the psychosocial profile of women with FMS and to see how the attributions, perceived social support and cognitive biases of women with FMS are related to internalizing ratings of depression and anxiety. The current study included a sample of women with FMS from a local support group and a control group to examine how women with FMS differed from controls with respect to psychosocial variables, and to determine the relationship between these variables. Women with FMS reported a higher external locus of control, lower levels of adaptive cognitive bias, less perceived family support and lower mood than controls. Correlations between these variables were examined within the FMS group, and it was found that an external locus of control was significantly associated with higher ratings of anxiety and depressed mood. These results suggest that beliefs about locus of control and perceived family support of women with FMS may importantly impact their health outcomes, and that treatments related to locus of control and advocating for family support may considerably improve the quality of life of patients with FMS.
\end{abstract}

Key Words: Fibromyalgia; Internalizing symptoms; Locus of control; Psychosocial; Social support

Cibromyalgia syndrome (FMS) is a disease with a complex etiology that is characterized by symptoms of widespread pain and fatigue (1). Diagnosis is currently based on criteria proposed by the American College of Rheumatology and includes a history of chronic pain for three months and pain sensitivity to $4 \mathrm{~kg}$ of pressure at more than 11 of 18 tender points (2). FMS also includes pain in the form of enhanced perception of a distressing body sensation, with an absence of discernible pathology or known cause (3). The prevalence of FMS in the general population is at least $2 \%$. It increases with age and women are four to seven times more likely to be affected by the condition than men (4). Risk factors for the development of FMS include physical trauma, febrile illness or a family history of FMS (5). FMS affects health broadly, including both physical and psychological wellbeing. The purpose of the present study was to examine the psychosocial functioning of women with FMS.

\section{Clinical symptoms associated with FMS}

While the central features of FMS are independent of psychological status, it has been suggested that psychological factors may influence pain severity (6). Like most chronic pain diagnoses, the clinical manifestations of FMS are more complex than body pain alone. Associated symptoms can include

\section{Comprendre le profil psychosocial des femmes atteintes du syndrome de fibromyalgie}

\begin{abstract}
Le syndrome de fibromyalgie (SFM) est une maladie d'étiologie complexe, caractérisée par des symptômes de douleur et de fatigue généralisées. Le SFM est plus fréquent chez les femmes. La dépression et l'anxiété ont toutes deux été associées de façon indépendante à la gravité de la douleur dans les symptômes de SFM. L'objectif de la présente étude était d'examiner le profil psychosocial des femmes atteintes de SFM et de voir en quoi les attributions, le soutien social perçu et les biais cognitifs des femmes atteintes de SFM sont liés à l'internalisation des indices de dépression et d'anxiété. La présente étude comparait un échantillon de femmes souffrant de SFM membres d'un groupe local d'entraide et des témoins; elle visait à analyser de quelle façon les femmes atteintes de SFM diffèrent des témoins en ce qui a trait aux variables psychosociales afin de déterminer les liens entre ces variables. Les femmes atteintes de SFM ont manifesté un locus de contrôle externe plus élevé, des degrés moindres de biais cognitifs adaptatifs, la perception d'un soutien familial insuffisant, de même qu'une humeur moins bonne que les témoins. Les corrélations entre ces variables ont été examinées dans le groupe affecté par la SFM et on a découvert qu'un locus de contrôle externe était significativement associé à des taux plus élevés d'anxiété et d'humeur dépressive. Ces résultats donnent à penser que les perceptions du locus de contrôle et du soutien familial chez les femmes souffrant de SFM exerceraient un impact important sur leur pronostic et que des traitements axés sur le locus de contrôle et la promotion du soutien familial pourraient améliorer considérablement leur qualité de vie.
\end{abstract}

disordered sleep, cognitive dysfunction, dizziness, headaches, depression, anxiety and irritable bowel syndrome (5). These associated symptoms contribute to the complexity of FMS and the difficulty in providing effective symptom management. Accordingly, FMS requires a multidimensional treatment focus and an appreciation of patients' psychosocial context.

\section{Psychosocial variables}

By definition, pain has interrelated sensory and affective components (7). Thus, it is not surprising that the presence of affective disorders, maladaptive reactions to distress, cognitive factors and poor coping strategies may promote the development of chronic pain in women (8). When compared with patients who have other pain diagnoses, such as cervical pain, headache, thoracic pain, lumbar pain, and upper and lower extremity pain, women with FMS reported the most difficulties on psychosocial measures (9). Moreover, the perception of not having social support has also been associated with chronic widespread pain (8). It is therefore important to understand the psychosocial characteristics of women with FMS.

FMS has been found to be comorbid with certain psychiatric disorders, including depression and anxiety. Comorbidity with depression ranges from $28.6 \%$ to $70 \%$ across studies

${ }^{1}$ Department of Psychology, Faculty of Health; ${ }^{2}$ LaMarsh Centre for Research on Violence and Conflict Resolution, York University; ${ }^{3}$ Scientific

Staff, Psychiatry Research, Hospital for Sick Children, Toronto, Ontario

Correspondence: Jill Shuster, BSB 291 Department of Psychology, York University, 4700 Keele Street, Toronto, Ontario M3J 1 P3.

Telephone 416-736-2100 ext 40217, fax 416-736-5814, e-mail jshust@yorku.ca 
$(10,11)$. More recently, it has been found that $30 \%$ to $45 \%$ of patients with FMS suffer from depression, stress and anxiety (12). It has also been found that anxiety and depression are independently associated with pain severity in FMS (13). High levels of depression and anxiety in patients with FMS were found to be associated with more physical symptoms and poorer functioning than pain controls (14). Comprehensive treatment of FMS should therefore examine affective distress as well as experience of pain (15). An understanding of how psychosocial variables are interrelated in FMS will lead to an improved biopsychosocial conceptualization of the syndrome.

Locus of control orientation is relevant to the experience of persistent pain. Individuals with an internal locus of control believe that a positive cause and effect relationship exists between their own behaviour and the outcomes they experience (16). Alternatively, people with an external locus of control perceive a lack of relationship between their behaviours and consequent outcomes. Outcomes in this case may be perceived as being controlled by sources external to an individual, such as powerful others or by chance factors such as fate or luck (17). Individuals with an internal locus of control who experience chronic pain are likely to believe that their own efforts will affect their pain and are therefore more likely to adapt active coping strategies $(18,19)$. They are also more likely to describe their pain as less frequent and less intense (20).

In a study measuring locus of control related to health (21), it was reported that patients with FMS were more externally oriented than patients with arthritis. Another study measuring locus of control (16) found that patients with FMS who had an external locus of control scored higher on a measure of helplessness, suggesting that locus of control may be related to cognitive styles associated with depression. Individuals with an internal locus of control believe that their own actions can affect the future course of pain. They can therefore develop strategies to deal with pain (16).

Perceived social support is another important variable affecting women with FMS. Specifically, it has been found that greater levels of perceived social support were associated with lower levels of depression, helplessness, mood disturbance and impact of FMS (22). Satisfactory social support has also been found to be significantly associated with depressed mood and pain intensity in patients experiencing chronic pain (23). Therefore, social support plays an important role in coping with the core symptoms of FMS and other associated symptoms.

Specific cognitive biases, such as overgeneralization, selective abstraction, arbitrary inference, minimization of positive assets or consequences, and maximization of negative assets or consequences, have been hypothesized to play a role in generating and maintaining symptoms of depression (24). The Cognitive Bias Questionnaire (CBQ; 25) was designed to measure cognitive biases associated with depression along two dimensions - depression and cognitive distortion. The depression cognitive bias refers to depressed affect rather than depressive syndrome, which includes the full complement of symptoms in the clinical range (25). Cognitive distortion is defined as the presence of inferences "that are unwarranted in light of the available information" (25).

To date, the role of cognitive bias in maintaining symptoms of depression and anxiety has not been extensively examined in women with FMS. In one study examining personality styles associated with depression in depressed and nondepressed women with FMS, and women with depression without FMS, as well as healthy controls, women with FMS had significantly lower levels of dysfunctional attitudes compared with patients with depression, but had elevated levels compared with healthy controls (26). A second study examining cognitive appraisals in women with FMS found that the effect of these appraisals may induce depression in FMS patients (27). Cognitive bias in relation to negative thinking may be an important psychosocial variable related to internalizing symptoms.

\section{Purpose and predictions of the present study}

The goal of the present study was twofold. First, a sample of women with FMS was compared with a control sample with respect to key psychosocial variables (locus of control, depressive cognitive bias, perceived social support, depression and anxiety) to determine which variables helped to distinguish women with FMS from healthy controls. Second, the interrelationships between the attribution, social support and cognitive bias variables (with the internalizing variables depression and anxiety) were examined in the clinical subsample. Then, the relation between the attribution, social support and cognitive bias variables, as well as ratings of depression and anxiety in women with FMS, was examined to determine predictors of these internalizing ratings.

First, it was predicted that women with FMS would have significantly greater external control, greater distorted and depressed cognitive biases, lower mood and higher levels of worry when compared with women in a control group. It was also predicted that they would report less perceived social support from family and friends. Second, it was predicted that higher ratings of anxiety and depression would be significantly correlated with an external locus of control, lower perceived social support and a greater depressed distorted cognitive bias in women with FMS. In addition, external locus of control, lower perceived social support, and a greater distorted and depressed cognitive bias would be significant predictors of low mood and high anxiety.

\section{METHODS}

\section{Participants}

Seventy-eight women with FMS (mean $[ \pm$ SD] age 43.9 \pm 17.9 years) and 28 control women (mean age $34.4 \pm 18.7$ years) participated in the present study. Participants were between the ages of 18 and 75 years. The mean ages of the women in the FMS and control groups differed significantly $(t[110]=2.54$, $\mathrm{P}=0.013)$; therefore, age was controlled for in the group comparisons. The women with FMS were recruited from a local support group for women with FMS as well as through a Web site for women with FMS set up by one of the authors (JM). Participants in the control group were recruited from support staff at the local university as well as through friends and relatives of the FMS group. All participants were recruited between September 2004 and April 2005 and gave informed consent. The study protocol was approved by the Human Participants Review Sub-Committee at York University (Toronto, Ontario).

Demographic characteristics of the FMS and control groups are presented in Table 1 . The majority of the women in the 
FMS group were divorced (64.1\%). Almost $40 \%$ of the women had completed a university degree and $47.4 \%$ were not currently working, while $19.1 \%$ were working full-time. Most women $(47.4 \%)$ reported that they were currently experiencing a low level of pain. In the control group, the majority of the women $(57.1 \%)$ were living with someone and were working full-time $(67.9 \%)$. Many women $(28.6 \%)$ had completed high school while other women $(53.6 \%)$ had completed university.

\section{Measures}

Demographics: A questionnaire was designed to collect demographic information, including age, sex, marital status, living arrangements, education level, employment status and profession.

Locus of control: Two locus of control questionnaires were used in the study. The Adult Nowicki-Strickland InternalExternal Control Scale (ANSIE; 27) was used to examine the internal and external loci of control. This self-report questionnaire consists of 40 items requiring yes or no answers. Internal reliability ranges from 0.74 to 0.86 . Scores range from 0 , indicating an internal locus of control, to 40 , indicating an external locus of control.

The Multidimensional Health Locus of Control (MHLC) scale (28) was designed to measure beliefs about the controllability of health issues. It consists of 18 items and each item is rated from 1 (strong disagree) to 6 (strong agree). The questionnaire yields scores on three dimensions of locus of control - internal, powerful other and chance. Higher scores reflect higher externality. Internal consistency reliability using Cronbach's alpha ranged from 0.67 to 0.77 .

Depression and anxiety questionnaires: The Center for Epidemiologic Studies Depression Scale (CES-D) (29) from the National Institute of Mental Health assesses how frequently an individual felt depressed in the past week. The questionnaire consists of 20 items that are rated from 0 (rarely) to 3 (most of the time) and the total score ranges from 0 to 60 . A score of 16 or greater indicates that the participant has experienced some degree of depression in the past week and higher scores indicate greater levels of depression.

The Penn State Worry Questionnaire (PSWQ; 30) is a 16 -item questionnaire that assesses an individual's tendency to worry excessively. The participant rates each statement on a five-point scale, on which a greater score indicates higher levels of worry. Reliability ranges from 0.86 to 0.93 .

Perceived social support: Two questionnaires, the Perceived Social Support (PSS) Friend Scale and PSS Family Scale (PSS-Fa) were administered (31). They consist of 20 items each and they measure how the participant perceives support fulfilled by friends and family. Participants respond to each item by answering yes, no or 'don't know'. A higher score reflects more perceived social support. The reliability on the PSS-Fa ranges from 0.88 to 0.91 and on the PSS Friend Scale ranges from 0.84 to 0.90 .

Cognitive biases: The CBQ (24) measures negative thinking and cognitive biases believed to be associated with depression, independent of inappropriate affect. The scale lists six negative situations, three of which focus on interpersonal situations and three that are achievement oriented. Each situation then lists four questions that represent all combinations of the two
TABLE 1

Demographics of the fibromyalgia syndrome (FMS) and control groups

\begin{tabular}{|c|c|c|}
\hline & FMS, $n=78$ & Controls, $n=28$ \\
\hline Mean age, years, mean \pm SD & $43.90 \pm 18.86$ & $41.8 \pm 10.4$ \\
\hline \multicolumn{3}{|l|}{ Marital status, n (\%) } \\
\hline Single & $4(5.1)$ & $5(17.9)$ \\
\hline Divorced & $50(64.1)$ & $3(10.7)$ \\
\hline Living with someone & $6(7.7)$ & $16(57.1)$ \\
\hline Widowed & $6(7.7)$ & $3(10.7)$ \\
\hline Married & $10(12.8)$ & $1(3.6)$ \\
\hline No response & $2(2.6)$ & $0(0)$ \\
\hline \multicolumn{3}{|l|}{ Highest level of education, $\mathrm{n}(\%)$} \\
\hline Less than high school & $4(5.1)$ & $1(3.6)$ \\
\hline High school completed & $21(26.9)$ & $8(28.6)$ \\
\hline Some college & $2(2.6)$ & $0(0)$ \\
\hline College completed & $13(16.7)$ & $4(14.3)$ \\
\hline Some university & $2(2.6)$ & $0(0)$ \\
\hline University completed & $31(39.7)$ & $15(53.615)$ \\
\hline No response & $5(6.4)$ & \\
\hline \multicolumn{3}{|l|}{ Employment, n (\%) } \\
\hline Homemaker & $12(15.4)$ & $2(7.1)$ \\
\hline Student & $3(3.8)$ & $0(0)$ \\
\hline Not currently working & $37(47.4)$ & $4(14.3)$ \\
\hline Part-time work & $10(12.8)$ & $3(10.7)$ \\
\hline Full-time work & $15(19.2)$ & $19(67.9)$ \\
\hline No response & $1(1.3)$ & $0(0)$ \\
\hline \multicolumn{3}{|l|}{ Level of pain reported, $\mathrm{n}(\%)$} \\
\hline Low pain & $37(47.4)$ & \\
\hline Moderate pain & $17(21.8)$ & \\
\hline Strong pain & $22(28.2)$ & \\
\hline No response & $2(2.6)$ & \\
\hline
\end{tabular}

dimensions of depression and distortion - depressed nondistorted, depressed distorted, nondepressed nondistorted and nondepressed distorted. Participants are asked to respond to the questions as if they were in each particular situation.

The following is a summarized example of an interpersonal situation. A couple who recently began dating is out for dinner and the woman seems quieter than usual. The man inquires, and the woman says she is having trouble at work. Four questions follow the above situation, each with four response options (depressed nondistorted, depressed distorted, nondepressed nondistorted and nondepressed distorted). The four questions require the participant to take the perspective of the man in the situation and make assumptions based on the woman's behaviour. In a sample question pertaining to why the woman has not called, the depressed distorted response was "All I can think about is that she must not care about me," the depressed nondistorted response was "I feel unhappy about it but figure that things sometimes do not happen exactly the way one would like," the nondepressed distorted response was "I imagine that she thinks so highly of me that she sometimes is afraid of risking rejection or pushing me too hard" and the nondepressed nondistorted response was "I decide I don't really know why and figure I should call her."

Scores are summed for each of the four depressed distorted categories and can range from 0 to 23. A higher score indicates a greater cognitive bias in each area. The reliability is 0.62 to 0.69 . 
TABLE 2

Group comparisons between the fibromyalgia syndrome (FMS) and control groups on psychosocial measures with age as a covariate

\begin{tabular}{lccccc}
\hline & FMS & $\mathbf{n}$ & Controls & $\mathbf{n}$ & $\mathbf{F}$ \\
\hline Age, years & $43.90 \pm 17.86$ & 78 & $34.44 \pm 18.72$ & 28 & $6.45^{\star}$ \\
Locus of control & & & & & \\
ANSIE & $13.56 \pm 4.93$ & 78 & $8.87 \pm 4.25$ & 28 & $17.33^{\star *}$ \\
MHLC internal health LC & $22.69 \pm 6.22$ & 78 & $25.94 \pm 3.72$ & 28 & $7.66^{* *}$ \\
MHLC powerful others LC & $14.73 \pm 5.16$ & 78 & $13.94 \pm 3.97$ & 28 & 0.35 \\
MHLC chance LC & $18.36 \pm 4.85$ & 78 & $15.56 \pm 4.81$ & 28 & $8.99^{* *}$ \\
Cognitive biases & & & & & \\
Depressed distorted & $1.96 \pm 2.21$ & 78 & $1.79 \pm 1.98$ & 28 & 0.04 \\
Nondepressed distorted & $2.24 \pm 1.55$ & 78 & $1.85 \pm 1.26$ & 28 & 1.22 \\
Depressed nondistorted & $5.88 \pm 3.08$ & 78 & $4.88 \pm 2.31$ & 28 & 3.40 \\
Nondepressed nondistorted & $12.88 \pm 3.90$ & 78 & $14.44 \pm 3.36$ & 28 & $3.81^{*}$ \\
Perceived social support & & & & & \\
Family & $11.08 \pm 6.23$ & 77 & $14.56 \pm 5.37$ & 28 & $7.23^{* *}$ \\
Friends & $9.96 \pm 4.52$ & 75 & $11.61 \pm 3.94$ & 28 & 2.57 \\
Internalizing symptoms & & & & & \\
CES-D & $40.84 \pm 11.26$ & 78 & $28.23 \pm 6.30$ & 28 & $42.21^{\star *}$ \\
PSWQ & $54.32 \pm 14.67$ & 78 & $50.35 \pm 13.66$ & 28 & 2.19 \\
\hline
\end{tabular}

Data presented as mean $\pm S D$ unless otherwise stated. ${ }^{*} P<0.05 ;{ }^{*} P<0.01$. ANSIE Adult Nowicki-Strickland Internal-External Control Scale; CES-D Center for Epidemiologic Studies Depression Scale; LC Locus of control; MHLC Multidimensional Health Locus of Control; PSWQ Penn State Worry Questionnaire

\section{Group comparisons}

\section{RESULTS}

One-way independent sample ANOVAs were conducted to examine differences between the FMS and control groups on the psychosocial variables. Because the two groups differed significantly in age, age was used as a covariate in the analyses. The results of the group comparisons are presented in Table 2.

On the locus of control variables, women with FMS $(13.56 \pm 4.93)$ scored higher on the ANSIE control scale than women in the control group $(8.87 \pm 4.25)$, demonstrating greater external locus of control; $\mathrm{F}(1,108)=17.33, \mathrm{P}<0.001$. Women in the control group $(25.94 \pm 3.72)$ had a greater internal locus of control as measured by the MHLC internal health locus of control than women with FMS $(22.69 \pm 6.22) ; \mathrm{F}(1,110)=7.66$, $\mathrm{P}=0.01$. Women in the FMS group $(18.36 \pm 4.85)$ scored higher on the MHLC chance locus of control than women in the control group (15.56 \pm 4.81$) ; \mathrm{F}(1,110)=8.99, \mathrm{P}=0.003$.

On the cognitive biases measures, women with FMS $(12.88 \pm 3.90)$ scored significantly lower than the control group $(14.44 \pm 3.36)$ on the nondepressed nondistorted subscale; $F(1,10)=3.81, P=0.05$. Women with FMS $(5.88 \pm 3.08)$ showed a trend toward higher depressed nondistorted cognitive bias than the control group $(4.88 \pm 2.31)$ on the depressed nondistorted subscale; $F(1,110)=3.40, P=0.09$. No significant group differences were found on the depressed distorted or nondepressed distorted subscales.

In the area of perceived social support, women in the control group (14.56 \pm 5.37$)$ scored higher than women with FMS $(11.08 \pm 6.23)$ in the area of family $F(1,109)=7.23, P=0.01$. No significant group differences were found in the area of perceived social support from friends.
TABLE 3

Pearson correlations between internalizing variables and nonaffect variables in women with fibromyalgia syndrome

\begin{tabular}{lcc}
\hline & \multicolumn{2}{c}{ Internalizing variables $(\mathbf{r})$} \\
\cline { 2 - 3 } & CES-D & PSWQ \\
\hline Locus of control & $0.53^{\star *}$ & $0.37^{\star *}$ \\
ANSIE & $-0.23^{*}$ & 0.12 \\
MHLC internal health locus of control & 0.10 & $0.20^{*}$ \\
MHLC powerful other locus of control & $0.21^{*}$ & 0.11 \\
MHLC chance locus of control & & \\
Cognitive biases & $0.26^{\star *}$ & $0.35^{\star *}$ \\
Depressed distorted & $0.34^{\star *}$ & $0.36^{\star *}$ \\
Depressed nondistorted & -0.05 & $-0.19^{*}$ \\
Nondepressed distorted & $-0.39^{\star *}$ & $-0.41^{\star *}$ \\
Nondepressed nondistorted & & \\
Perceived social support & $-0.51^{\star *}$ & $-0.39^{\star *}$ \\
Family & 0.17 & -0.08 \\
Friends & & \\
\hline
\end{tabular}

${ }^{*} P<0.05 ;{ }^{*} P<0.01$. ANSIE Adult Nowicki-Strickland Internal-External Control Scale; CES-D Center for Epidemiologic Studies Depression Scale; MHLC Multidimensional Health Locus of Control; PSWQ Penn State Worry Questionnaire

Women in the FMS group $(40.84 \pm 11.26)$ reported greater ratings of depression than women in the control group $(28.23 \pm 6.30) ; \mathrm{F}(1,110)=42.21, \mathrm{P}<0.001$. Age was a significant covariate; $F(1,110)=4.10, P=0.05$. There were no significant group differences with respect to amount of worry, as measured by the PSWQ.

Relationship between internalizing symptoms and measures of attributions, social support and cognitive biases

To examine the second hypothesis regarding associations between internalizing ratings and measures of attributions, social support and cognitive biases with women with FMS, two-tailed Pearson product correlations were performed. The results are presented in Table 3.

Ratings of depression, as measured by the CES-D, were positively correlated with an external locus of control, as measured by the ANSIE $(r=0.53, P<0.001)$, negatively correlated with an internal locus of control, as measured by the internal health locus of control of the MHLC $(r=-0.23, \mathrm{P}=0.017)$ and positively correlated with having a chance locus of control $(\mathrm{r}=0.21$, $\mathrm{P}=0.029$ ). Ratings of depression were also negatively correlated with perceived social support from family $(\mathrm{r}=-0.51, \mathrm{P}<0.001)$. Finally, ratings of depression were significantly positively correlated with depressed distorted cognitive bias $(r=0.26$, $\mathrm{P}<0.001)$, depressed nondistorted cognitive bias $(r=0.34$, $\mathrm{P}<0.001)$ and negatively correlated with nondepressed nondistorted cognitive bias $(r=-0.39, \mathrm{P}<0.001)$.

Ratings of worry, as measured by the PSWQ, were positively correlated with an external locus of control, as measured by the ANSIE $(r=0.37, \mathrm{P}<0.001)$ and positively correlated with the MHLC powerful others locus of control $(\mathrm{r}=0.20, \mathrm{P}=0.04)$. Greater levels of worry were negatively correlated with greater levels of perceived social support from the family $(r=-0.39$, $\mathrm{P}<0.001$ ). Finally, ratings of worry were significantly positively correlated with depressed distorted cognitive bias $(\mathrm{r}=0.35$, $\mathrm{P}<0.001)$, depressed nondistorted cognitive bias $(\mathrm{r}=0.36$, $\mathrm{P}<0.001)$ and negatively correlated with a nondepressed nondistorted cognitive bias $(r=-0.41, \mathrm{P}<0.001)$. 
To further examine which of the significantly correlated nonaffect variables were independent predictors of internalizing ratings, two simultaneous regression analyses were conducted to predict ratings of depression and anxiety. The results of the regressions are presented in Table 4.

The regression predicted ratings of depression, as measured by the CES-D. ANSIE, MHLC internal health locus of control, MHLC chance locus of control and PSS-Fa, as well as the depressed distorted, depressed nondistorted and nondepressed nondistorted cognitive biases, were entered as predictors. Together, they accounted for $40 \%$ of the variance of the CES-D. It was found that ANSIE, MHLC internal health locus of control and PSS-Fa were significant predictors of ratings of depression.

The regression predicted ratings of anxiety, as measured by the PSWQ, ANSIE, MHLC powerful others locus of control and PSS-Fa, as well as depressed distorted, depressed nondistorted and nondepressed nondistorted cognitive biases were entered as predictors. Together, they accounted for $28 \%$ of the variance. None of the independent variables were significant predictors of ratings of anxiety.

\section{DISCUSSION}

Women with FMS had a significantly higher external locus of control, higher ratings of depressed mood, lower perceived social support from family and lower nondepressed nondistorted cognitive bias. Second, within the group of women with FMS, it was found that a greater external locus of control and lower perceived support from family, as well as greater depressed distorted and depressed nondistorted cognitive biases, and a lower nondepressed nondistorted cognitive bias, were significantly correlated with higher ratings of depressed mood and anxiety. Finally, it was found that an external locus of control and lower perceived social support from family were significant predictors of ratings of depression, and that while the model predicting ratings of anxiety was significant, none of the individual predictors were significant.

\section{Psychosocial profile of women with FMS}

The present study compared women with FMS with a control group in respect to psychosocial variables and found that women with FMS have a greater external locus of control, lower levels of perceived social support, lower nondistorted nondepressive cognitive bias and higher ratings of depressed mood. This is consistent with previous studies that found women with FMS to have a greater external locus of control (16). It also supports previous studies examining social support in women with FMS. While it has been found that high-quality social support was associated with better psychological outcomes (22), the current findings add to this by highlighting that while high-quality social support is associated with better outcomes, women with FMS report experiencing significantly lower levels of social support from both family and friends. Because women with FMS were more likely to be divorced than women in the control group, this could also impact perceived social support within the group of women with FMS.

Interestingly, women with FMS did not have a greater depressed distorted cognitive bias compared with women in the control group, despite having higher ratings of depression. They did have lower nondepressed nondistorted cognitive bias,
TABLE 4

Regression analyses predicting internalizing symptoms from nonaffect variables

\begin{tabular}{|c|c|c|}
\hline Dependent measure & $\begin{array}{c}\text { Standardized } \\
\text { beta weight }\end{array}$ & $t$ \\
\hline \multicolumn{3}{|l|}{ CES-D } \\
\hline ANSIE & 0.28 & $2.81^{*}$ \\
\hline MHLC internal health locus of control & -0.17 & $-2.08^{*}$ \\
\hline MHLC chance locus of control & -0.06 & 0.70 \\
\hline Perceived Social Support - Family Scale & -0.31 & $-2.86^{*}$ \\
\hline \multicolumn{3}{|l|}{ Cognitive bias } \\
\hline Depressed distorted & -0.13 & -0.84 \\
\hline Depressed nondistorted & -0.09 & -0.56 \\
\hline Nondepressed nondistorted & -0.28 & -1.26 \\
\hline \multicolumn{3}{|c|}{ Overall regression $F=9.67^{\star *}$, multiple $R=0.64$, multiple $R^{2}=0.40$} \\
\hline \multicolumn{3}{|l|}{ Penn State Worry Questionnaire } \\
\hline ANSIE & 0.15 & 1.46 \\
\hline MHLC powerful others locus of control & 0.17 & 1.95 \\
\hline Perceived Social Support - Family Scale & -0.15 & -1.33 \\
\hline \multicolumn{3}{|l|}{ Cognitive bias } \\
\hline Depressed distorted & 0.27 & 1.68 \\
\hline Depressed nondistorted & 0.32 & 1.77 \\
\hline Nondepressed nondistorted & 1.96 & 0.82 \\
\hline \multicolumn{3}{|c|}{ Overall regression $F=6.68^{* *}$, multiple $R=0.53$, multiple $R^{2}=0.28$} \\
\hline
\end{tabular}

suggesting that they are lower in the most adaptive cognitive bias compared with women in a control group. This finding is consistent with a study (25) that found a depressotypic personality style was related to depressive disorder, but not specifically to FMS. The study compared levels of depression and cognitive styles of patients with FMS with and without depression, and patients with major depressive disorder (25).

This finding could suggest that higher ratings of depression in women with FMS are related to factors other than maladaptive cognitive schemas, such as reduced ability to participate in enjoyable activities and lack of sleep due to pain. Supporting this idea, in a study of chronic pain outpatients (32), it was found that interference in involvement with important activities mediated much of the association between pain severity and depressed mood.

\section{Relation of attribution, social support and cognitive bias variables to internalizing symptoms}

Previous studies have established the comorbidity between FMS and depression $(8,9)$ and anxiety (13). The current study plays an important role in determining nonaffect variables, such as variables of attribution, social support and cognitive bias, that are related to internalizing symptoms and that predict ratings of depression and anxiety. An external locus of control, low nondepressed nondistorted cognitive bias and low perceived social support from family were all significantly correlated with greater ratings of both depression and anxiety. This similar pattern of findings for ratings of both depression and anxiety highlights that similar nonaffect variables are related to ratings of both internalizing symptoms.

A simultaneous regression was performed to predict ratings of depression, and an external locus of control and lower perceived social support from family were found to be significant 
predictors of ratings of depression. Both ratings of depression and a chronic pain condition can reduce an individual's sense of perceived control over the outcomes that they are experiencing. Therefore, it is likely that an external locus of control is both related and predictive of ratings of depressed mood. This relationship may be used to modify existing treatments so that they focus on increasing a patient's sense of self-efficacy to build a more internal locus of control. Preliminary evidence supports the effectiveness of altering the locus of control of patients experiencing chronic pain. In one study (33), chronic pain patients experienced a significant increase in internal locus of control after participating in a four-week multidisciplinary pain program consisting of daily exercise, relation and coping skills training, and cognitive behavioural therapy. It will be important to examine how these findings extend to treatment of patients with FMS.

Because women with FMS often have family histories of FMS and have experienced childhood adversities (34), it is likely that these factors impact their perceived level of familiar social support and its link to depressive symptoms. It is therefore important to take into account the unique familiar experiences of women with FMS in treatment to help them modify the way they perceive their support. This is a particularly important aspect of treatment given that the quality of social relationships in women with FMS is related to better psychological outcomes $(22,23,35)$. Additionally, it has been found that an increase in family stressors is associated with an increase in health problems in a sample of women with FMS (36). The reduction of stressors and the building of resilience in families with FMS may play a role in increasing the quality of social support perceived by women with FMS.

Greater depressed distorted, depressed nondistorted and lower nondepressed nondistorted cognitive biases were significant correlates of ratings of both anxiety and depression. The cognitive biases examined in the CBQ were constructed to measure depressive distortions hypothesized by Beck (23) to play an important role in the cause of maintenance of dysphoria and other symptoms of depression. Women with FMS have lower levels of adaptive cognitive bias compared with women in a control group and this, in addition to greater levels of depressed distorted and depressed nondistorted cognitive biases, is significantly correlated with ratings of both depression and anxiety. These findings support developing greater levels of this most adaptive cognitive bias in treatment in addition to decreasing cognitive biases associated with depressive thinking, which were also significantly related to symptoms of anxiety and depression.

The results from the current study have important implications for treatment of FMS. Current research suggests that optimal intervention for FMS includes a nonpharmacological treatment, such as cognitive behavioural therapy, in addition to medication management for sleep and pain symptoms (37). Integrated treatment should also include patient education and aerobic exercise, which have been shown to be effective in reducing FMS symptoms (38). Based on the current study, it will be important to include treatment components that focus on developing an internal sense of control, adaptive cognitive biases and increased perceived social support from family members. To increase perceived support from family members, treatment could include a family component.

\section{Limitations and future directions}

The current study plays an important role in characterizing the psychosocial profile of women with FMS and determining the relationship between psychosocial variables and internalizing ratings. It is unclear from the current study whether this psychosocial profile is present before symptoms of FMS or whether it develops in response to symptoms of FMS. An understanding of the unique characteristics of these women is important in providing effective treatment, regardless of whether the psychosocial profile existed previously or is a consequence of symptoms of FMS.

There are a number of directions for future studies. First, a prospective study measuring symptom severity and level of functioning as well as internalizing symptoms and variables of attribution, social support and cognitive bias could determine how symptoms of FMS develop and the role of these nonaffect variables in mediating these symptoms to gain more insight into whether depression is causally related to FMS either before or after FMS symptoms develop. Second, measuring symptom severity, and physical and psychological functioning, would allow a further understanding of how psychosocial and internalizing variables affect the level of functioning in women with FMS. Third, because the sample of women in the current study was recruited from a local support group, it will be important to examine how the findings from the current study generalize to other women with FMS. It is possible that women in a support group differ from other women with FMS on certain variables, such as level of education, amount of pain experienced or length of time experiencing pain. Fourth, in further examining the role of social support in women with FMS, it will be important to take into account their unique stage of life. The participants in the study ranged from 18 to 75 years of age and therefore could have a variety of different needs from their social support. A further examination of what women with FMS lack from their social supports could play a role in informing treatment to increase the quality of perceived social support. Finally, future studies should also measure pain in the control group, given the high prevalence of pain in the general population. This could further clarify whether the psychosocial profile is specific to women with FMS or more related to pain levels experienced.

\section{CONCLUSIONS}

The current study further characterizes the psychosocial profile of women with FMS who were recruited from a local support group. This profile is characterized by an external locus of control, lower perceived social support from family and a lower nondepressed nondistorted cognitive bias when compared with women in a control group. The study also provided support for the relationship between attribution, social support and cognitive bias variables and internalizing ratings of depression and anxiety. The current findings play an important role in developing a comprehensive treatment that addresses the variety of psychological symptoms associated with FMS.

ACKNOWLEDGEMENTS: The authors thank Sandy Parks for her help with data management and Start-up Funds from York University (Toronto, Ontario) for supporting this project, as well as the study participants. 


\section{REFERENCES}

1. Starlanyl D, Copeland ME. Fibromyalgia and Chronic Myofascial Pain: A Survival Manual, 2nd edn. Oakland: New Harbinger Publications, 2001:18-22.

2. Wolfe F, Smythe HA, Yunus MB, et al. The American College of Rheumatology 1990 criteria for the classification of fibromyalgia: Report of the multicenter criteria committee. Arthritis Rheum 1990;33:722-6.

3. Jamison JR. A psychological profile of fibromyalgia patients: A chiropractic case study. J Manipulative Physiol Ther 1 999;22:454-7.

4. Wolf F, Ross K, Anderson J, Russell IJ, Hebert L. The prevalence and characteristics of fibromyalgia in the general population. Arthritis Rheum 1995;38:19-28.

5. Russell J. Fibromyalgia syndrome: Presentation, diagnosis, and differential diagnosis. Prim Psychiatry 2006;13:40-5.

6. Yunus MB, Ahles JC, Masi AT. Relationship of clinical features with psychological status in primary fibromyalgia. Arthritis Rheum 1991;34:15-21.

7. International Association for the Study of Pain. Classification of Chronic Pain 2008 approved modifications. <http://www.iasp-pain. org/AM/Template.cfm?Section=Home\&Template $=\mathrm{CM} /$ ContentDisplay.cfm\&CONTENTID $=6636>$ (Version current at July 15, 2008).

8. Bergman S. Psychosocial aspects of chronic widespread pain and fibromyalgia. Disabil Rehabil 2005;27:675-83.

9. Porter-Moffitt S, Gatchel RJ, Robinson RC, et al. Biopsychosocial profiles of different pain diagnostic groups. J Pain 2006;7:308-18.

10. Ahles TA, Yunus MB, Masi AT. Is chronic pain a variant of depressive disease? The case of primary fibromyalgia syndrome. Pain 1987;29:105-11.

11. Yunus MB. Role of central sensitization in symptoms beyond muscle pain, and the evaluation of a patient with widespread pain. Pract Res Clin Rheumatol 2007;21:481-97.

12. Kurtze N, Gundersen KT, Svebak S. The role of anxiety and depression in fatigue and patterns of pain among subgroups of fibromyalgia patients. Br J Med Psychol 1998;71:185-94.

13. White KP, Nielson WL, Harth M, Ostbye T, Speechley M. Chronic widespread musculoskeletal pain with or without symptoms of fibromyalgia: Psychological distress in a representative community adult sample. J Rheumatol 2002;29:588-94.

14. Thieme K, Turk DC, Flor H. Comorbid depression and anxiety in fibromyalgia syndrome: Relationship to somatic and psychosocial variables. Psychosom Med 2004;66:837-44.

15. Crisson JE, Keefe FJ. The relationship of locus of control to pain coping strategies and psychological distress in chronic pain patients. Pain 1988;35:147-54.

16. Levenson H. Activism and powerful others: Distinctions within the concept of internal-external control. J Pers Assess 1974;38:377-83.

17. Jensen MP, Karoly P. Control beliefs, coping efforts, and adjustment to chronic pain. J Consult Clin Psychol 1991;59:431-8.

18. Haythronthwaite JA, Menefee LA, Heinberg LJ, Clark MR. Pain coping strategies predict perceived pain control. Pain 1998;77:33-9.

19. Toomey TC, Mann JD, Abashian S, Thompson-Pope S. Relationship between perceived self-control of pain, pain description and functioning. Pain 1991;45:129-33.
20. Gustafsson M, Faston-Johansson F. Pain intensity and health locus of control: A comparison of patients with fibromyalgia syndrome and rheumatoid arthritis. Patient Educ Couns 1996;29:179-88.

21. Franks HM, Cronan TA, Oliver K. Social support in women with fibromyalgia: Is quality more important than quantity? J Community Psychol 2004:32:425-38.

22. Lopez-Martinez AE, Esteve-Zarazaga R, Ramirez-Maestre C. Perceived social support and coping responses are independent variables explaining pain adjustment among chronic pain patients. J Pain 2008;9:373-9.

23. Beck AT. Cognitive therapy: Nature and relation to behavior therapy. Behav Ther 1970;1:184-200.

24. Krantz S, Hammen C. Assessment of cognitive bias in depression. J Abnorm Psychol 1979;88:611-9.

25. Nordahl HM, Stiles TC. Personality styles in patients with fibromyalgia, major depression and healthy controls. Ann Gen Psych 2007;6:9.

26. Okifuji A, Turk DC, Sherman JJ. Evaluation of the relationship between depression and fibromyalgia syndrome: Why aren't all patients depressed? J Rheum 2000;27:212-9.

27. Nowicki S, Duke MP. The Nowicki-Strickland life span locus of control scales: Construct validation. In: Lefourt HM, ed. Research with the Locus of Control Construct. New York: Academic Press, 1983:9-43.

28. Wallston KA, Wallson BS, DeVellis R. Development of the Multidimensional Health Locus of Control (MHLC) Scales. Health Educ Monogr 1978;6:160-70.

29. Radloff LS. The CES-D scale: A self-report depression scale for research in the general population. Appl Psychol Meas $1977 ; 1: 385-401$.

30. Meyer TJ, Miller ML, Metzger RL, Borkovec TD. Development and validation of the Penn State Worry Questionnaire. Behav Res Ther 1990;28:487-95.

31. Procidano ME, Heller K. Measures of perceived social support from friends and from family: Three validation studies. Am J Community Psychol 1983;11:1-24.

32. Cannella DTL, Lobel M, Glass P, Lokshina I, Graham JE. Factors associated with depressed mood in chronic pain patients: The role of intrapersonal coping resources. J Pain 2007;8:256-62.

33. Coughlin AM, Badura AS, Fleischer TD, Guck TP. Multidisciplinary treatment of chronic pain patients: Its efficacy in changing patient locus of control. Arch Phys Med Rehabil 2000;81:739-40.

34. Imbierowicz K, Egle UT. Childhood adversities in patients with fibromyalgia and somatoform pain disorder. Eur J Pain 2003; 7:113-9.

35. Reich JW, Olmsted ME, van Puymbroeck CM. Illness uncertainty, partner caregiver burden and support, and relationship satisfaction in fibromyalgia and osteoarthritis patients. Arthritis Rheum 2006;55:86-93.

36. Preece JC, Sandberg JG. Family resilience and the management of fibromyalgia: Implications for family therapy. Contemp Fam Ther 2005;27:559-75.

37. Rossy LA, Buckelew SP, Dorr N, et al. A meta-analysis of fibromyalgia treatment interventions. Ann Behav Med 1999;21:180-91.

38. Goldenberg DL. Multidisciplinary modalities in the treatment of fibromyalgia. J Clin Psychiatry 2008;69:30-4. 


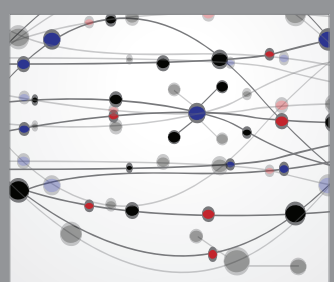

The Scientific World Journal
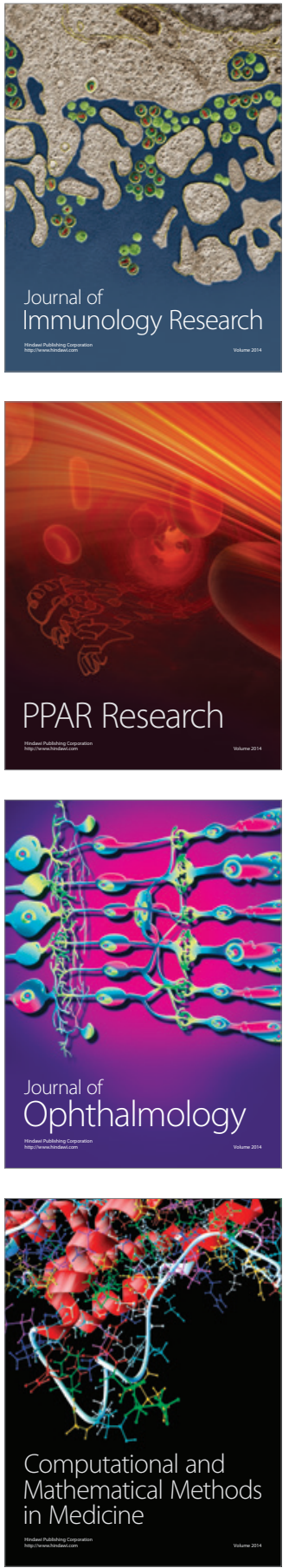

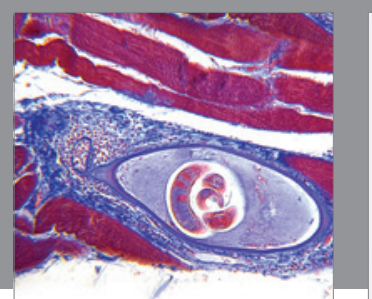

Gastroenterology Research and Practice

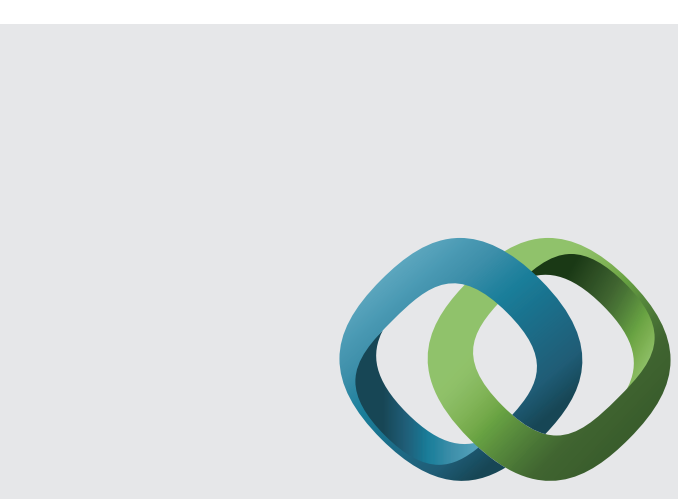

\section{Hindawi}

Submit your manuscripts at

http://www.hindawi.com
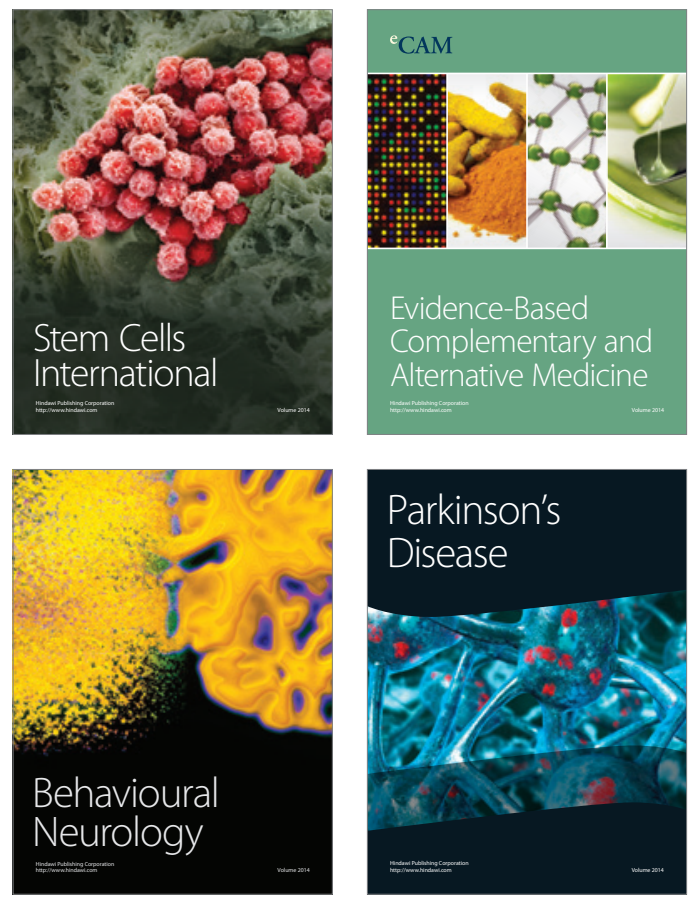
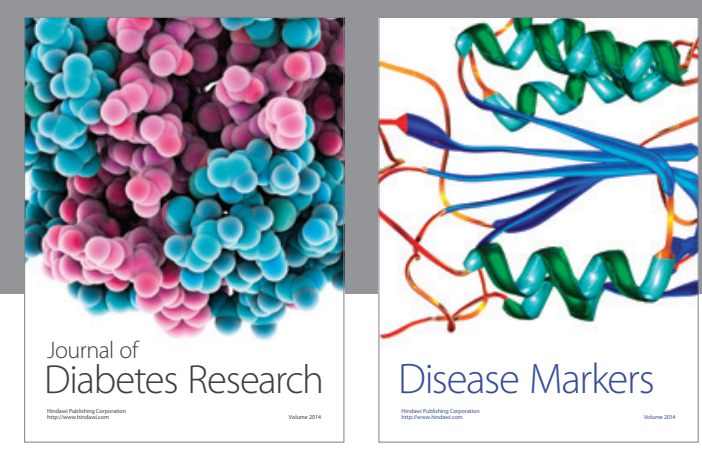

Disease Markers
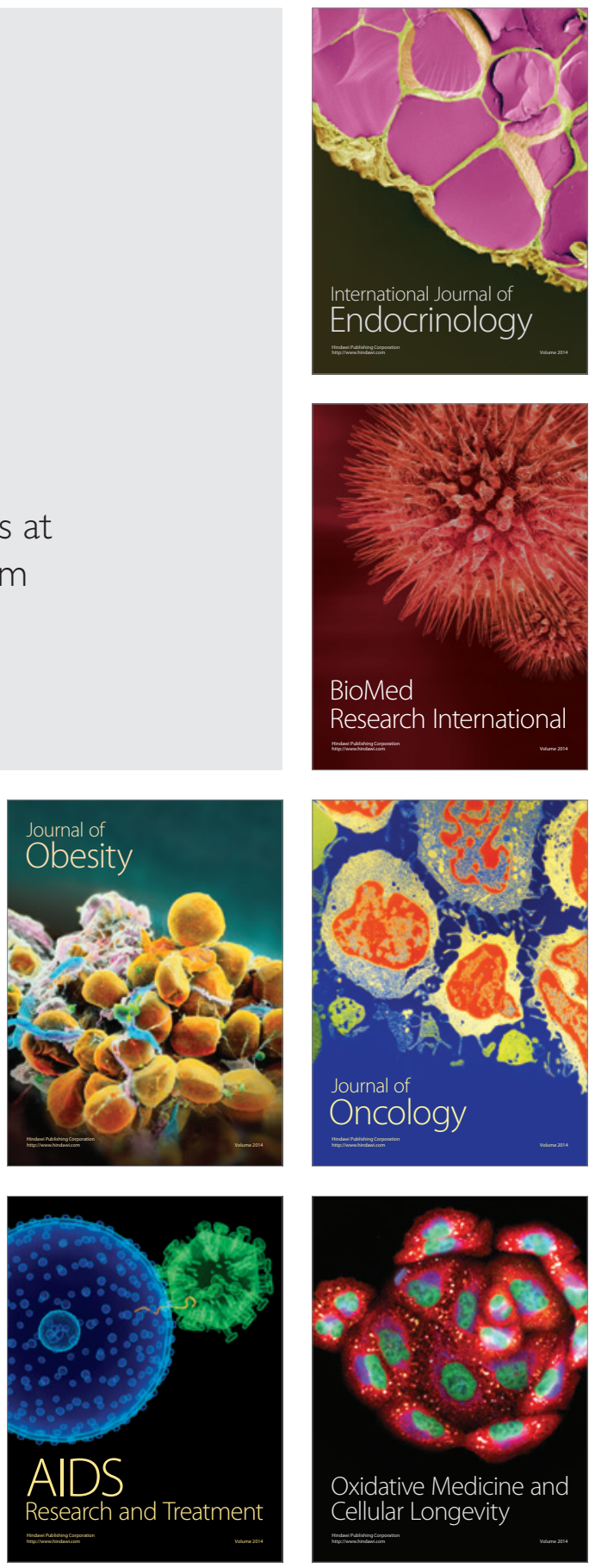